\title{
Facilitators and Barriers to Antiretroviral Therapy Adherence among Ghanaian Patients: A Multi-Case Study
}

\author{
Lily Yarney ${ }^{1}$, Angela K. Amankwah², Chuks J. Mba ${ }^{3}$, Kwame Asamoah ${ }^{4}$ and Justice N. \\ Bawole $^{5}$
}

${ }^{1}$ Department of Public Administration and Health Services Management, University of Ghana Business School, Legon, Accra.

babyaraba95@yahoo.com¹

${ }^{2}$ Department of Public Administration and Health Services Management, University of Ghana Business School, Legon, Accra.

${ }^{3}$ Association of African Universities

${ }^{4}$ Department of Public Administration and Health Services Management, University of Ghana Business School, Legon, Accra.

${ }^{5}$ Department of Public Administration and Health Services Management, University of Ghana Business School, Legon, Accra.

\section{Abstract}

The only remedy to manage AIDS remains ART, making adherence to ART paramount in AIDS management. Non-adherence can impede the sustainability of programmes intended at successful HIV and AIDS care. We studied individual, social and service delivery factors influencing adherence to ART. Mixed method involving 133 participants was used, data were analysed using SPSS version 18.0. There were statistically significant relationship between availability of drugs: privacy, relations with health professionals, counselling services, and adherence to ART $((p=0.008, p=0.00 \mathrm{I}, p=0.008$ and $p=0.018$ respectively). Although age, gender, and perceived efficacy and need for ART were not significantly related to adherence ( $\mathrm{p}>.05$ in all cases), the qualitative findings indicated otherwise. For AIDS patients, ART is tantamount to life, thus, stakeholders should place priority on availability of ARVs and well trained personnel to deliver efficient and quality senvices to allay the fears of patients.

Keywords: Facilitators, Barriers, ART Adherence, Ghana

\section{Introduction}

HIV and AIDS have become a health scare in the world since its discovery in the early 1980s (UNAIDS \& WHO, 2003), with an infection and death rates of 6,800 and 5,700 persons respectively per day, due to insufficient access to treatment and prevention of HIV and AIDS (UNAIDS 20I5; UNAIDS \&WHO, 2007).

HIV has been and is still a challenge in Ghana, thus, in 201 I, it was estimated that 559,007 people were living with the disease (NACP, 20II). The number of infected persons receiving treatment was 225,478 as at the end of 201I (National AIDS Commission, 2013). The occurrence of the disease seems to be on a downward trend, however, the pattern may be described as irregular since prevalence rates have been rising and falling over a period of time. Hence, HIV prevalence dropped from $3.6 \%$ in 2003 to $2.7 \%$ in 2005 , it then increased to $3.2 \%$ in 2006 and reduced to $2.2 \%$ in 2008 . Also, the distribution of the disease is not even across the country. There are variances in the regional distribution of the dominance of the disease. Some parts record high prevalence, principally mining and border towns, while others have lower rates. A major reason for high prevalence in these areas is thought to be the increased commercial activities in those areas, with its attendant attraction of people from all walks of life. A survey conducted in the country revealed that the occurrences of the disease increased in some regions while the Brong-Ahafo remained the same (Ghana AIDS Commission, 20I2).

Since there is no cure for HIV, adherence to Antiretroviral Therapy (ART) is important to reduce the spread of the virus to enable infected persons live a normal and prolonged life. Highly Active Antiretroviral Therapy (HAART) is currently the most effective regimen for reducing mortality and opportunistic infections among HIV patients. Antiretroviral therapy can be started when patients including positive pregnant women have a CD4 count below $350 \mathrm{cells} / \mathrm{ml}$ (Ministry of Health/Ghana Health Service, 20I0). Since the introduction of ART in the management of HIV, it has produced a remarkable 
result. Reports by the UNAIDS (20I2) suggested that since 1999 ART has increased the life expectancy rate of people living with the disease in low and middle income countries. It has been reported that about 8 million people had access to ART by the end of $201 \mathrm{I}$.

Antretroviral therapy was not part of Ghana's public healthcare system until June 2003, when the health ministry earmarked two places in the Manya Krobo district of the Eastern Region as pilot sites. The treatment included counselling and testing, management of sexually transmitted diseases and prevention of mother-to-child transmission (PMTCT). It was realized that the therapy had made improvements in the management of the disease at the pilot sites. To ensure a reduction in the spread and mortality caused by the disease, treatment sites were expanded and since its introduction, the treatment sites as at December, 2009 increased from 2 to about 138. The improvements in access to ART drugs have reduced the occurrence of new infection especially in PMTCT (Ampofo, 2009).

Treatment is by complying with drug combination therapy. For adults, it is recommended that two of nucleoside reverse transcriptase inhibitors (NRTls) plus a non-nucleoside reverse transcriptase inhibitor be administered as fixed dose combination in the initial stage of treatment. Treatment for the second phase consists of two nucleoside reverse transcriptase inhbitor (NRTls) plus Ritonavir - boosted protease Inhibitor (PI) (WHO 20I5; 20I3).

A lot of factors affect the treatment success of HIV. Among the factors, strict adherence to treatment regimen appears to be crucial. The reason being that a high level of adherence is required for the drugs to work effectively, which abo ensures the avoidance of development of drug resistance (Nachega et al., 2006). However, the realization of effective complance by infected people to the requirements of the treatment regime depends on their ability to accept the treatment recommendation. This has proven to be a big challenge for persons living with HIV (PLHIV) (Mills et al., 2006). Although ART has been proven to be effective, countries which have been able to implement it have all come up against the challenge of patient adherence to treatment programme. Thus, non-adherence accounts for the treatment failure in most cases (Obirikorang, Selleh, Abledu, \& Fofie, 2013). The existence of non-adherence can also impede the sustainability of programmes intended at successful HIV and AIDS care. We therefore carried out this study to provide empirical basis for assisting people living with HIV and AIDS to adhere to antiretroviral therapy, so as to improve their health outcomes and reduce mortality among this vulnerable group.
Literature Review and Theoretical Framework

There are various definitions of adherence to treatment that suggest that adherence relies on the patient as well as the health professional. Health professionals are to communicate well to patients in terms of how to take medications as well as other recommendations associated with the drugs. The patient on the other hand, must understand the process and accept to comply with directives given. Adherence in this study is defined as the willingness of an individual to take medication as directed by the health service provider and comply with treatment requirements.

Drug adherence depends on both the patients and the relation that exists between providers and patients. Understanding the patient's perspective and reactions after commencing treatment may aid treatment adherence. Studies that applied the objective adherence measure revealed that about $70 \%$ of prescribed doses are taken in the treatment of HIV (Horne, Cooper, Gellaitry, Date \& Fisher, 2007).

A lot of research has been done in the area of treatment adherence (Horne et al., 2007; Chesney et al., 2000; Conway, 2007; Mills, et al., 2006), but most of these studies were carried out in developed countries and Southern Africa. Als o, compliance with treatment therapy can be viewed from three main perspectives: the individual level, the social level and facility level (Posse et al., 2008), however, most of the studies carried out on adherence especially in low and middle-income countries identified factors such as financial constraints, stigma and inadequate information as hindrance to adherence (Nachega, 2006). These factors tend to gain prominence in places with high poverty levels, which generally fits the circumstances of many African countries. Ghana for instance has dealt with financial access by subsidizing the cost of ART, hence, PLHIV have access to free health care as they receive free supply of antiretroviral (ARV) drugs.

Since the implementation of HAART in Ghana in 2003, studies on HIV have been directed at reducing new infections. Hence, there are reports on enhanced effect in months into therapy, but diminutive data have been published bearing in mind ART adherence and issues concerning treatment (Ohene \& Forson, 2009). This has the potential to impact negatively on HIV treatment effectiveness and needs to be urgently addressed. Again, most of the studies in Ghana considered only one facility, and considered individual factors (Obirkorang et al., 2013; Ohene \& Forson, 2009). The present study goes beyond what has been done in Ghana by using a multi-case study to identify whether there are differences in adherence to ART at the facility level, and investigates further on the social and 
facility related factors that may influence ART adherence, thus, expanding the scope of research on the subject matter so as to uncover widely the barriers to adherence and make recommendations to address them as a way forward to improving treatment effectiveness.

The study is based on the health belief model (HBM) which is a useful instrument in understanding and explaining the factors that influence ART adherence (legede, 1998). HBM postulates that behaviour that is related to health is dependent on four critical areas of a person's perception. These are: the seriousness of an inherent illness, tractability of the illness, advantage of embarking on an action to avert the occurrence of the illness, and the hurdles to taking that action. It is therefore assumed that adherence to ART is influenced by a number of psychological variables, and proven mechanisms to diminish within the social system, the occurrence of HIV and AIDS.

According to the model, human beings are confronted with alternative actions, but would often choose the one that would be most beneficial (Munro, Lewin, \& Volmink, 2007). Thus, persons living with HIV and AIDS would adhere to ART treatment when they hold certain beliefs about ART. These include perceived consequences of nonadherence, the severity of AIDS and its social consequences, trust in effectiveness of ART adherence as the right step to take, witnessing the illness and death of other non-adherent patients and perceived gains of adherence and barriers to adherence. It is thus, construed that the total effect of these beliefs and perceptions which may take their source from the individual himself, his social interactions and facility factors impacts on the probability of AIDS patients adhering to ART. Hence, the HBM throws light on the relationship between AIDS patients' beliefs and perceptions, and ART adherence by lending a route to comprehend and predict the factors that would influence ART adherence.

\section{Data and Methods}

\section{Study Design and Study Areas}

A multi-case study design was employed in the study. This design permitted inter-facility comparison of adherence to antiretroviral therapy. The study areas which were purposively selected are the Brong-Ahafo Regional and Municipal Hospitals. These hospitals were chosen because they are designated facilities for HIV management in the Brong-Ahafo Region of Ghana, thus there is easy access to HIV and AIDS patients.

Study Population Sampling and Sample Size

The study population consisted of all clients diagnosed as HIV positive who attended ART clinic at the
Sunyani Regional and Municipal Hospital, and the health professionals who attended to them were included in the study to ascertain their views on the factors that influence ART adherence.

HIV and AIDS is associated with stigma and discrimination, thus, individuals with the disease usually dissociate themselves from any activity that is likely to expose their HIV positive status. This makes it difficult to sample HIV and AIDS Patients using probability sampling technique, therefore, purposive sampling which is a non-probability sampling technique was used to select HIV positive adults 18 years old and above who were willing to be part of the study. Because non-probability sampling techniques do not require rigorous sample size calculations, 120 respondents consisting of 60 participants from each of the two study facilities, and satisfied the inclusion criteria were involved in the quantitative study whist 13 others made up of 8 patients and 5 healthcare professionals who had a minimum of one year working experience with HIV treatment were abo selected purposively to take part in the qualitative study. The healthcare professionals comprised of the HIV coordinator at the Sunyani Regional Hospital and the HIV counsellor at the Municipal Hospital, a representative from the pharmacy department in charge of ART adherence counselling at the Municipal Hospital, a clinician in charge of clinical consultation and a nurse in charge of HAART clinic, both at the Regional Hospital.

\section{Data Collection Methods and Instruments}

The study employed mixed method for data collection. The quantitative part of the study used self-designed questionnaire administration. The questionnaire was divided into five parts: the first part sought to find out individual characteristics including demography and disease factors; the second part considered social factors such as the existence of support and stigma, culture and religion; the third part focused on service delivery factors including relationship with health professionak, availability of drugs and health promotion activities which had the potential to influence adherence to ART; and the fifth part was on patients' adherence to ART in three and seven day assessment.

The Qualitative aspect took the form of one-onone in-depth interviews with an interview guide. The in-depth interviews were held at the study facilities with patients and health workers to gather detailed information on individual, social and facility factors that determine adherence to ART.

\section{Ethical Consideration and Research Process}

Prior to the commencement of the study in 2014, approval was sought from the Ghana Health Service with the study protocol. Following this, permission was granted from the hospital authorities of the study 
facilities before data collection. Every individual respondent also gave a written or oral consent as per their preference before participation. Before participants were interviewed, each was given a consent form to read and sign. For individuals who could not read, the purpose of the study was explained to them and if they accepted to partake, their thumbprints were taken, anonymity and confidentiality were assured for all participants.

Pre-test of the research tools was carried out to ensure reliability of the data collection instruments. The questionnaires were then revised for data collection. One-on-one interview questionnaire was conducted for each of the 120 participants for the quantitative study, either in English language or in the local (twi) anguage as per the choice of the participant. Indepth interviews were also conducted with $8 \mathrm{HIV}$ patients and 5 healthcare professionals.

\section{Data Analysis}

The Statistical Package for Social Sciences (SPSS) version 18.0 was used to analyse the quantitative data. Trusting that clients are honest with how they took their medication, self-reported adherence to medication was used to assess ART adherence among the study participants. Adherence to ART was analysed in three day and seven day assessment. The seven day assessment was used to put participants into two categories - adherent and non- adherent. Fisher's Exact Test of independence (data were categorical and nominal) was used to find out the relationship between individual, social, and service delivery factors that influence adherence to ART at $95 \%$ confidence interval. The same method was used to assess the differences in adherence between the two study health facilities.

The individual factors consisted of gender, education, perceived efficacy of ART, and perceived need for ART. The Social factors were measured in terms of support from significant others, stigma, disclosure of HIV positive status, belief in spirituality and traditional medicine, and service delivery factors were measured using relations with Health Professionals, perceptions about service provision and privacy, availability of drugs, and counselling services.
In-depth interviews were recorded with a digital recorder and transcribed. Data were analysed manually and categorized into themes with the man objectives as a guide. Where necessary, some responses were quoted verbatim whilst others were edited to improve readability. Results of the study were triangulated where appropriate.

\section{Results}

Demographic characteristics of respondents

The majority $(65.8 \% ; 79 / / 20)$ of respondents were females. Their ages ranged from 18 to 50 years and above. Sixty-five percent of them $(78 / / 20)$ had junior or senior high education, only about $6 \%(7 / / 20)$ had tertiary education whist the remaining $29 \%$ (35/I20) had primary or no formal education. Most of the respondents (about 7/\%; 85/I20) are Christians, 25\% $(30 / 120)$ are Muslim, and the rest are Traditional or other worshippers, (see Table I).

\section{Adherence to ART}

All the respondents (100\%) adhered to ART treatment in the three day assessment, however, $25 \%$ (30/I20) were not adherent in the seven day assessment. For those who defaulted, the man reasons for missing medication were forgetfulness and travelling or busy schedule (3.3\%; $10 / 30$ and $53.3 \%$; 16/30) respectively. These were consistent with responses from the in-depth interviews as interviewees indicated forgetfulness, travelling and busy schedules as the man causes of missing their medications. Some patient interviewees abo indicated that they have been informed that missing just a day dose would not harm them so they sometimes missed dose if medication coincided with social activities.

Table I: Demographic Characteristics of Respondents

\begin{tabular}{|llll|}
\hline Variables & Category & Frequency & $(\%)$ \\
\hline Gender & Female & 79 & 65.8 \\
& Male & 41 & 34.2 \\
Total & & 120 & 100.0 \\
\hline Age & $18-29$ & 32 & 26.7 \\
& $30-39$ & 33 & 27.5 \\
& $40-49$ & 34 & 28.3 \\
Total & 50 and above & 21 & 17.5 \\
\hline
\end{tabular}




\begin{tabular}{|llll|} 
& & & \\
\hline Level of Education & Primary & 28 & 23.3 \\
& Junior high & 45 & 37.5 \\
& Senior high & 33 & 27.5 \\
& Tertiary & 7 & 5.8 \\
Total & No formal education & 7 & 5.8 \\
& & 120 & 100.0 \\
\hline Employment status & Employed & 103 & 85.8 \\
Total & Unemployed & 17 & 14.2 \\
& & 120 & 100 \\
\hline Religion & & 85 & 70.5 \\
& Christianity & 30 & 25.0 \\
& Islam & 1 & 0.8 \\
Total & Traditional & 4 & 3.3 \\
\hline
\end{tabular}

\section{Individual factors and adherence to ART}

The relationship between adherence to ART and gender, age, and educational level were all not statistically significant $(p=0.317 ; p=0.520 ; p=0$. 195 respectively) (Table 2). However, findings from indepth interviews with health professionals indicated that age and gender have influence on adherence to ART. Four $(80 \%)$ out of the 5 health professionals interviewed indicated that young men do not usually adhere to HIV treatment. According to them, women regardless of their age are adherent to ART than men, their health records depict high turn up rate for women than men. Thus:

'Young men find it very difficult accepting their HIV positive status when they find out after testing in the first place. Some will come back and tell you that they don't believe that they have HIV because they feel healthy and strong. Hence, they may agree during counselling to come for treatment but they do not adhere to taking the drugs as scheduled, or will not return for refill" (Health Professional, Sunyani Municipal Hospital)

"If you go through the books you will realize that women adhere much more than men. Men especially the young ones don't want to come for treatment when they are diagnosed, because they don't want their friends to know that they are HIV positive, they may be afraid of stigma and the fact that young ladies might not want to enter into a relationship with them. But for the women because they are mostly pregnant at the time of diagnosis, they most of the time return for treatment to protect their babies from acquiring the infection, and so they adhere to treatment." (Health professional, Sunyani Municipal Hospital)

"Women are much more adherent than men. Men like to take risks so they wait until they are ill before they take their medication or visit the facility for treatment." (Health professional, Sunyani Regional Hospital)

Perceived Efficacy and Perceived Need for Treatment and Adherence to ART

There was no statistically significant relationship between perceived efficacy and ART adherence ( $p=$ $0.062)$, and perceived need and ART adherence $(p=$ 0.736 ) as indicated in Table 2.

Responses from the in-depth interviews with patients however, varied from these findings. Some of them indicated that when they started the treatment and their health condition improved, they had the urge to adhere to treatment so they can stay healthy.

".... As for the ART drugs, they are very good, without them I would not be alive today. I was on treatment for about 9 years prior to taking ART drugs, but I was not healthy. I had low weight and chronic illnesses, currently, I am very healthy. I have good appetite for food which also boosts my immune system, so I'm always encouraged by my improved health condition to take my ART medications." (Patient, Sunyani Municipal Hospital)

“...... Initially I experienced drug side effects so the drugs were changed, now I am very healthy. How can I even think of missing my medications, they give me life" (Patient, Sunyani Regional Hospital).

"The drugs are difficult to take especially when you start at first, but once your system adjusts to them and they are working for you, then you realise you can never do away with them, so you feel the need for them especially when they are getting finished" (Patient, Sunyani Regional Hospital) 
"........In fact, the drugs work and that encourages me to stick to them. I'm even afraid that if I don't take them for one day, my health condition will deteriorate" (Patient, Sunyani Municipal Hospital)

\section{Social Factors and Adherence to ART}

Support, Stigma, Disclosure of HIV Positive Status and Adherence to ART

There was no statistically significant difference between existence of support ( $P=0.96)$, stigma $(P=$ 0.96), disclosure of HIV positive status $(P=0.059)$ and adherence to ART. Thus, social support in the form of support from other family members and friends and stigma after disclosure of HIV positive status to someone either in the family or outside the family had no influence on adherence to ART (Table 3). These findings again were not supported by the qualitative part of the study. The in-depth interviews revealed that support from loved ones in the form of fnancial aid, encouragement, information, reminders to take medications improved adherence to ART. Some also indicated existence of support as a major facilitator of adherence to ART. Respondents who were presumed to have acquired the disease from their unfaithful partners received immense support from family members.

"My husband was diagnosed of HIV and he died months after his diagnosis. After his death, I was sick for a long time and admitted at the hospital. At that point, I was also diagnosed of HIV. Regardless of my status, my family members gave me all the assistance I needed. They have been my source of motivation. Currently, I visit hospitals to counsel other people with the disease to adhere to medication" (patient, Sunyani Regional Hospital)

".... I receive support from my family members and a nurse friend as well. When I am unable to go for my medication at the hospital, my sister takes them on my behalf. The nurse friend also gives me encouragement to cope with the disease. Without the support from these people I would not be alive today." (Patient, Sunyani Municipal Hospital).

Al the health professionals interviewed abo clearly indicated that support from 'relevant others' aids ART adherence.

"Some patients have mental conditions as a result of the disease so they may not appreciate the need to take medication, so the supporter helps in adhering to medication as scheduled." (Health professional, Sunyani Regional Hospital)

Table 2: Individual Factors and Adherence to ART

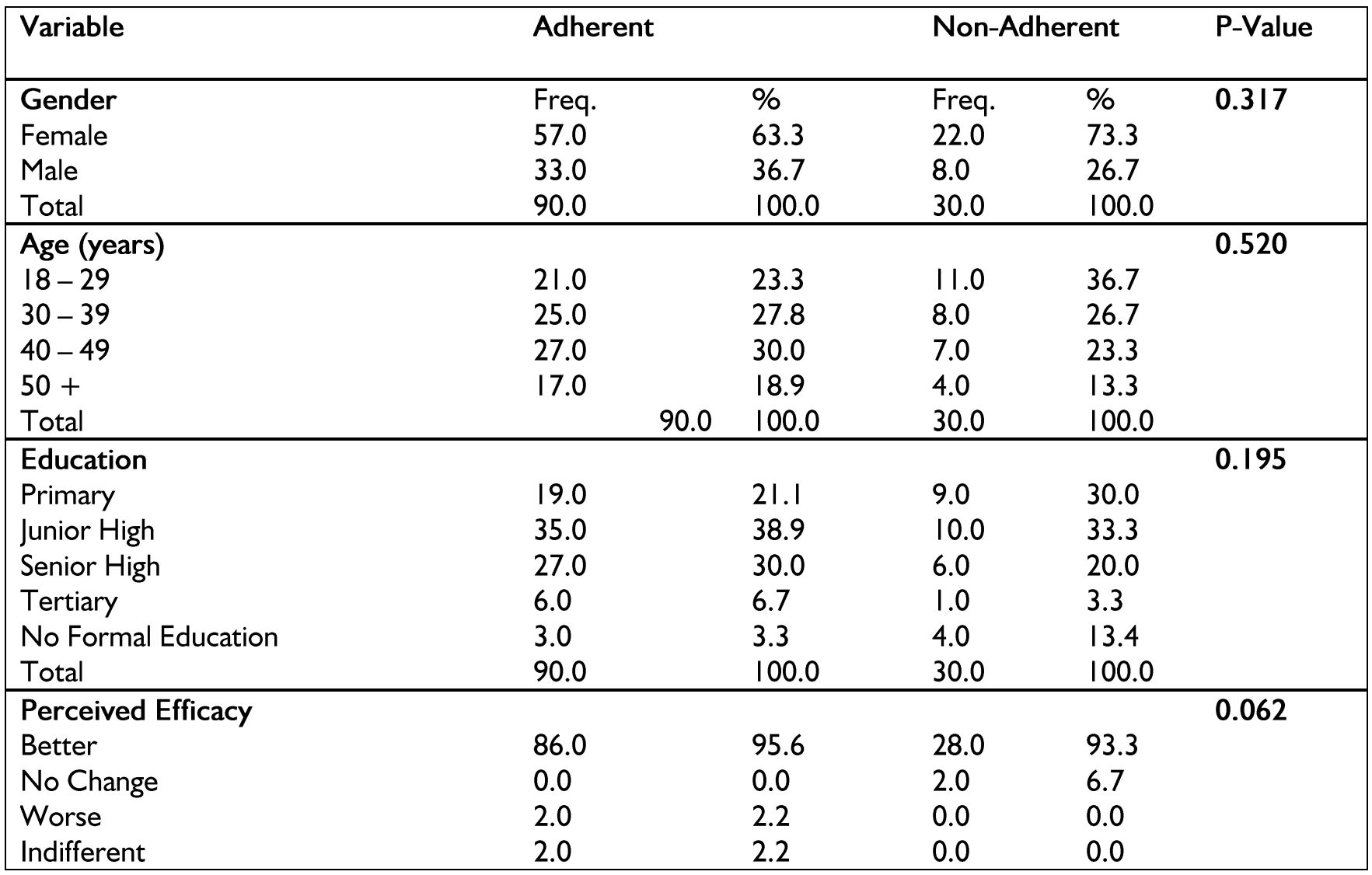




\begin{tabular}{|llllll|}
\hline Total & 90.0 & 100.0 & 30.0 & 100.0 & \\
\hline Perceived Need for Treatment & & & & & 0.736 \\
Yes & 88.0 & 97.8 & 29.0 & 96.7 & \\
No & 2.0 & 2.2 & 1.0 & 3.3 & \\
Total & 90.0 & 100.0 & 30.0 & 100.0 & \\
\hline
\end{tabular}

Belief in Spirituality, Traditional Medicine, and Adherence to ART

Statistically, there was no significant rehationship between belief in spirituality and adherence to ART ( $p$ $=0.815)$. In the same vain there was no statistically significant relationship between belief in traditional medicine ( $p=0.084)$ and adherence to ART (Table 3 ). These fndings were not different from the fndings from the in-depth interviews with patients. Patient interviewees indicated that they did not rely on spiritual healing or traditional medicine as cure for HIV. Some however indicated that prayer is regarded as a complementary remedy to HIV cure.

"It is good to pray, but the medicine is important. Once you know your status you have to take the drugs as scheduled and pray that God in his mercies will heal you." (Patient, Sunyani Regional Hospital)

"I go to church and pray that I will be completely healed, but I still take my medications." (Patient, Sunyani Regional Hospital).

"As for traditional medicine, I have taken some before, and it was good for treating diarrhoea, but they are not as effective as the ART drugs, so I don't depend on traditional medicine anymore." (Patient, Sunyani Municipal Hospital).

"At times some priests tell you they can pray for you to be healed completely, and that will make you stop taking your medication, but that is not true, your condition might worsen, and may end up dying, so I don't believe in that kind of spiritual healing, that does not mean I don't believe in God." (Patient, Sunyani Municipal Hospital)

Interviews with the health professionals however, portrayed that belief in spirituality hindered their clients from adhering to treatment.

"Clients generally adhere to treatment, and when they get better, about $40 \%$ discontinue with the medication and resort to prayer camps for cure, they only return when their health condition deteriorates. By that time, some may not be eligible for ART treatment anymore and they die." (Health professional, Sunyani Municipal Hospital)

Service Delivery Factors and adherence to ART Relations with Health Professionals, Perceptions about Se rvice Provision and Privacy, and ART Adherence

There was a statistically significant relationship between relations of patients with health professionals and adherence to ART $(p=0.008)$. Also, perception about services and privacy in the facility had a statistically significant relationship with adherence to ART $(p=0.008$ and $p=0.001$ respectively) as shown in Table 4 .

Table 3: Social Factors and Adherence to ART

\begin{tabular}{|llllll|}
\hline Variable & Adherent & \multicolumn{5}{ll}{ Non-Adherent } & P-Value \\
\hline Existence of Support & Freq. & $\%$ & Freq. & $\%$ & 0.960 \\
Yes & 88.0 & 88.9 & 23.0 & 76.7 & \\
No & 10.0 & 11.1 & 7.0 & 23.3 & \\
Total & 90.0 & 100.0 & 30.0 & 100.0 & \\
\hline Existence of Stigma & & & & & 0.960 \\
Yes & 4.0 & 4.4 & 0.0 & 0.0 & \\
No & 77.0 & 85.6 & 24.0 & 80.0 & \\
No Response & 9.0 & 10.0 & 6.0 & 20.0 & \\
Total & 90.0 & 100.0 & 30.0 & 100.0 & \\
\hline Disclosure & & & & & 0.084 \\
Good Relation & 20.0 & 22,2 & 1.0 & 3.3 & \\
Receive Support & 59.0 & 65.6 & 23.0 & 76.7 & \\
Aid Adherence & 1.0 & 1.1 & 0.0 & 0.0 & \\
No Response & 10.0 & 11.1 & 6.0 & 20.0 & \\
Total & 90.0 & 100.0 & 30.0 & 100.0 & \\
\hline
\end{tabular}




\begin{tabular}{|c|c|c|c|c|c|}
\hline $\begin{array}{l}\text { Belief in Spirituality } \\
\text { Yes } \\
\text { No } \\
\text { Total }\end{array}$ & $\begin{array}{l}26.0 \\
64.0 \\
90.0 \\
\end{array}$ & $\begin{array}{l}28.9 \\
71.1 \\
100.0\end{array}$ & $\begin{array}{l}8.0 \\
22.0 \\
30.0 \\
\end{array}$ & $\begin{array}{l}26.7 \\
73.3 \\
100.0\end{array}$ & 0.815 \\
\hline $\begin{array}{l}\text { Belief in Traditional Medicine } \\
\text { Yes } \\
\text { No } \\
\text { Total }\end{array}$ & $\begin{array}{l}24.0 \\
66.0 \\
90.0\end{array}$ & $\begin{array}{l}26.7 \\
73.3 \\
100.0\end{array}$ & $\begin{array}{l}12.0 \\
18.0 \\
30.0\end{array}$ & $\begin{array}{l}40.0 \\
60.0 \\
100.0 \\
\end{array}$ & 0.084 \\
\hline
\end{tabular}

These results were also not too different from the fndings from the in-depth interviews. Participants expressed that there was a good relationship between them and their health providers. This relations hip enabled them to comply with medication requirements. Some patients however, indicated that some health workers do not treat them well, but this does not deter them from going to the hospital for their medication and taking them reguarly

'We don't have any problem with our health providers. Health workers attend to us very well. They keep our information private, and are good to us. We are able to tell them the challenges we face and they listen to us, so we are comfortable and we obey them by taking our medications as scheduled." (Patient, Sunyani Municipal Hospital)

"There are some few health workers who do not treat us with respect, and these are usually new staff, this does not affect the taking of my medication." (Patient, Sunyani Municipal Hospital)

\section{Availability of drugs, counselling, and adherence to ART}

Respondents receive $A R V s$ for free at the health facilities which in many ways contrbuted to adherence to ARV. However, they bear the cost for non-ARVs which are purchased outside the health facility. As indicated in Table 3, the availability of drugs had a statistically significant rebationship with adherence to ART $(p=0.008)$. There was also a statistically significant rebtionship between relevance of counselling and adherence to ART ( $p=0.018)$.
Responses from the in-depth interviews revealed that the facilities sometimes faced drug shortages. But drugs are dispensed such that every client received at least a month supply of drugs to enhance continuity of treatment. If a particular drug was out of stock, health professionals switch the regime and supply alternative drugs which alters the time intervals for refills as well. This initiative was regarded as a barrier to adherence by all patient in-depth interviewees.

"Initially, the doctors used to give 5 Months interval for appointment and we were given drugs to cover that period. Of late, the doctor can give 2 Months interval but the pharmacist dispenses drugs to cover for only two weeks. It makes it difficult adhering to these separate schedules. We travel long distances to attend ART services. I will appreciate if the system is revised to reduce transportation cost. Once you are not sick, the pharmacist should provide drugs to cover 6 months to enhance our ability to adhere to treatment requirements."(Patient, Sunyani Municipal Hospital).

Table 4: Service Delivery Factors

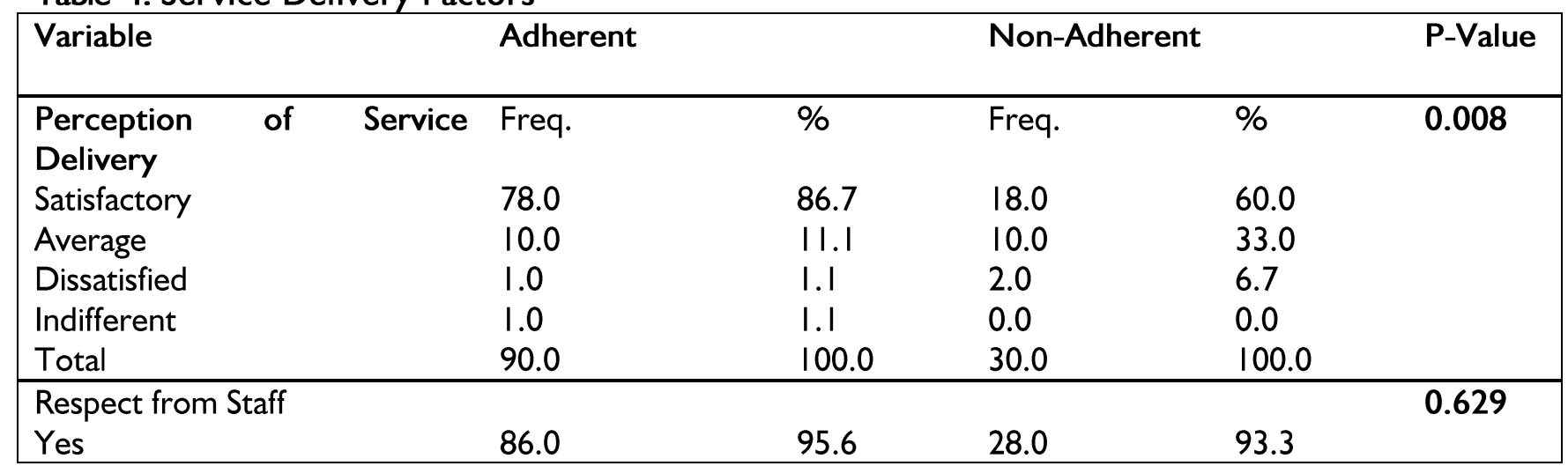

http://aps.journals.ac.za 


\begin{tabular}{|c|c|c|c|c|c|}
\hline $\begin{array}{l}\text { No } \\
\text { Total }\end{array}$ & $\begin{array}{l}4.0 \\
90.0 \\
\end{array}$ & $\begin{array}{l}4.4 \\
100.0\end{array}$ & $\begin{array}{l}2.0 \\
30.0 \\
\end{array}$ & $\begin{array}{l}6.7 \\
100.0\end{array}$ & \\
\hline Privacy & & & & & 0.001 \\
\hline Yes & 88.0 & 97.8 & 24.0 & 80.0 & \\
\hline No & 2.0 & 2.2 & 6.0 & 20.0 & \\
\hline Total & 90.0 & 100.0 & 30.0 & 100.0 & \\
\hline Satisfactory Communication & & & & & 0.065 \\
\hline Yes & 88.0 & 97.2 & 27.0 & 90.0 & \\
\hline No & 2.0 & 2.2 & 3.0 & 10.0 & \\
\hline Total & 90.0 & 100.0 & 30.0 & 100.0 & \\
\hline Supply of Drugs & & & & & 0.008 \\
\hline Yes & 81.0 & 90.0 & 21.0 & 70.0 & \\
\hline No & 9.0 & 10.0 & 9.0 & 30.0 & \\
\hline Total & 90.0 & 100.0 & 30.0 & 100.0 & \\
\hline Payment of Drugs & & & & & 0.562 \\
\hline Yes & 25.0 & 27.8 & 10.0 & 33.3 & \\
\hline No & 65.0 & 72.2 & 20.0 & 66.7 & \\
\hline Total & 90.0 & 100.0 & 30.0 & 100.0 & \\
\hline Affordability of Drugs & & & & & 0.397 \\
\hline Yes & 79.0 & 87.8 & 28.0 & 93.3 & \\
\hline No & 11.0 & 12.2 & 2.0 & 6.7 & \\
\hline Total & 90.0 & 100.0 & 30.0 & 100.0 & \\
\hline Regular counselling & & & & & 0.187 \\
\hline Yes & 85.0 & 94.4 & 30.0 & 100.0 & \\
\hline No & 5.0 & 5.6 & 0.0 & 0.0 & \\
\hline Total & 90.0 & 100.0 & 30.0 & 100.0 & \\
\hline Relevance of counselling & & & & & 0.018 \\
\hline Yes & 85.0 & 94.4 & 24.0 & 80.0 & \\
\hline No & 5.0 & 5.6 & 6.0 & 20.0 & \\
\hline Total & 90.0 & 100.0 & 30.0 & 100.0 & \\
\hline
\end{tabular}

The majority of factors that hindered adherence to ART were service delivery factors. About a third of respondents generally had no challenges with health professionals (34.2\%; $4 \mathrm{I} / \mathrm{I} 20)$. Those who expressed some challenges attributed them to delay at the pharmacy $(29.2 \% ; 35 / 120)$, delay in service delivery (I3.3\%; I6/I20), health workers not prompt to work $(8.3 \% ; 10 / / 20)$, and drug refil schedules and preferential treatment (I5.0\%; I8/I20). Transportation

cost $(29.3 \%$; $35 / 120)$, cost of non ARVs (I $0.8 \%$; $13 / \mid 20)$ and treatment requirements $(5.8 \% ; 7 / / 20)$ were also indicated as barriers.

Similar barriers were rased in the in-depth interviews. Respondents had a challenge with service delivery at the pharmacy. There were complaints that usually they spend almost the whole day at the clinic waiting for drugs. This was due to the fact that staff at the pharmacy do not start work early. Some were emphatic that they dodged their employers to go for

I'm satisfied with the treatment I receive from the health professionals. My major challenge is time spent at the pharmacy. I try to come early so I can go back to my daily activities but I end up spending the whole day at the clinic. Now the time is IIam the staff at the pharmacy are now coming to work. We have complained several times but nothing has been done about it." - (Patient, Sunyani Regional Hospital)

"When I go to work first, I cannot leave for the hospital, so I usually go to the hospital first and very early, so I can go to work, but here is the case where I always have to go to work very late if I have to visit the hospital, because there are a lot of delays in the service delivery in this facility. Presently, my boss is not nice to me because of my lateness to work." (Patient, Sunyani Regional Hospital). 
Differences in Adherence to ART among Patients of Sunyani Regional and Municipal Hospitals

No statistically significant difference in adherence to ART among respondents of the two study health facilities was found $(p=0.673)$.

\section{Discussion}

Antiretroviral therapy is an important management regime for HIV and AIDS especially in this era where a cure for HIV is yet to be realized. Thus, the drug combination therapy suppresses the virus in the blood stream, limiting its destructive ability on the immune system of the infected, and thereby preventing opportunistic infections. Information about the disease process, treatment procedure, drug resistance, nonadherence and its effects are vital for attaining compliance to ART. This information is usually well communicated to patients at the start of treatment for them to understand the rationale, however, many scholars assert that non adherence to ART is common among HIV and AIDS patients (Carlucci et al., 2006; Nachega et al., 2006; Olowookere et al., 2008). In this study, respondents exhibited knowledge on the need to adhere to ART, with the majority (75\%) adhering in the seven-day assessment. This is necessary if involvement of patients in HIV treatment is to be achieved to enhance their commitment to treatment (Machtinger \& Bangsberg, 2006), which is vital for effective treatment.

General drug complance is usually influenced by individual factors. Thus, daily activities like travels, busy schedules, funerals, and others as found in the study can make people forget to take their medication or leave them behind (Forgarty et al., 2002). On this, patients can be sensitized by their counsellors as a way of reminding them to taking their medications amidst these activities. Feeling of being healthy, and reluctance to disclose HIV positive status also affect adherence (Olowookere, Fatiregun, Akinyemi, Bamgboye, \& Osagbemi 2008). Studies have been carried out on the individual attributes that affect ART compliance (Boyarinova, 2007; Spirea et al., 2002; Murray et al., 2009; Grierson, Koelmeyer, Smith, \& Pitts, 20II; Lucas, Chaison, \& Moore 1999; Reif, Golin \& Smith 2005). Some identified gender, age, literacy level, employment, knowledge on the disease, treatment side effects as well as medication scheduling as factors that influence adherence.

In our study, the quantitative findings did not indicate statistically significant relationship between individual factors like age, gender, perceived efficacy and need for ART and adherence, however, the qualitative findings indicated associations between these variables and adherence to ART. Non adherence was associated with young men, and this was attributed by health professionals as young men being less capable of long term therapy, and fear of rejection and stigma from the society especilly from young women. Contrary to this finding, other studies indicate high non-adherence rates in women (Bailey et al., 2014; Murray et al., 20l0; Nagarina, Popenoe,Kilewo, Biberfeld, \& Ekstrom, 20I3; Hanif et al., 20I3). Some of the reasons being stigma and low empowerment on the part of women to access treatment especially in the developing world. Fogarty et al., (2002) however, disagree that gender has influence on adherence to ART and indicate age as a factor in adherence. What accounts for the disparity in these findings may be contextual, hence, it should be noted that women and men experience different forms of barriers when it comes to HIV issues (Ferguson, Stewart, Funkhouser, Westfall, \& Sagg, 2002), and therefore, interventions should be such that they address the specific needs of both men and women.

Perceived efficacy and need for ART was also regarded as factors that influence adherence by participants in the qualitative study. Individuals who regard ART as a curative measure usually discontinue treatment when their health condition improves (Gokran, Narkheda, Pardeshi, \& Doibale, 2012; Karcher, Odera, Kurz \& Harms 2007; Murphy et al., 2000). Similarly, there were some participants who discontinued treatment after observing improvement in their heath. Others too were motivated to adhere to ART because they saw improvement in their health. They were informed to adhere to prevent them from relapse. These people regarded ART as important because they had achieved beneft through the efficacy of treatment. Consistently some studies have identified that achievement or beneft derived from medication influence adherence to ART (Holstad, et al., 2006; Luszczynska, Sarkar \& Knoll, 2007; Simoni et al., 2006). Belief that ART is important to ensure good health is an important basis for adherence to ART. Thus, individuals who think they need to take medication only when they are sick, usually are nonadherent to ART (Murphy, Roberts, Martin, Marelich, \& Hoffman, 2000). This underscores the importance of persistent sensitization on the fact that ART does not cure, but manages HIV and AIDS and nonadherence can result in serious health consequences.

Social factors like absence of stigma (Curioso, Kepka, Cabello, Segura, \& Kurth, 2010; Rintamaki, Davis, Skripkauskas, Bennette, \& wolf, 2006), support by a significant other and disclosure of HIV positive status aid adherence (Afolabi, et al., 20I3; FredriksenGoldsen, et al. 20II; Nachegba et al., 2006). The service providers in this study seemed to be in the known as they indicated that as part of their treatment procedures, each client is asked to present a treatment supporter, whose duty is to monitor clients 
in the absence of a health professional. This strategy enabled respondents to have someone to support them. Some participants indicated in the qualitative study that less stigma after disclosure made it easier for them to adhere to treatment. They were able to disclose their status to family members and friends who in turn support them to adhere to treatment requirements. Disclosure of status led to support because health professionals pass confidants through series of counselling to inform them on how to care for people lining with HIV and AIDS. This could be the reason why there was less experience of stigma among study participants, amidst this, respondents were careful with making people identifying them as HIV and AIDS patients. Many people tend to conceal their treatment, seek treatment far away or wait till no one is watching before they take medication to prevent discrimination from their friends and loved ones. Thus, persistent stigma associated with HIV in the family and community is a drawback to treatment compliance (Mshana et al., 2006; Padarath, Searle \& Esu-Williams, 2006). Families and communities must therefore be continuously sensitized to eradicate stigma against HIV and AIDS patients.

Whilst some studies have found culture and religion as barriers to ART adherence (Olowookere, et al., 2008; Wanyama, et al., 2007; Walker et al., 2004), our findings on these indicated otherwise. Thus, reliance on spirituality and the use of traditional medicine were not common with respondents. Their decision to stick to $A R V s$ was influenced by counselling services, which convinced them that adhering to medication was the only way to live long in good health. However, some health professional indicated that their clients defaulted treatment because of reliance on spirituality, and these people usually revert to the health facilities for help that is impossible to provide.

Health professionals play a vital role in achieving optimal adherence to ART. The sort of rebation that exists between them and their clients influences clients' decision to continue or discontinue treatment (Beach, Keruly, \& Moore, 2006; Murphy et al., 2000). From the study, privacy and perception on services had statistically significant relationship with ART adherence $(p=0.00 \mathrm{I}$ and $p=0.008$ respectively). This was attributed to supportive non-judgmental care from health providers which sort to place clients' need frst. This assisted respondents to accept treatment procedure and adhere to them. It was emphasized in the qualitative study that information was kept confidential which made them express their challenges freely for them to be addressed, thus, confirming that trust, privacy and confidentiality with health professionals is associated with adherence to ART (Golin, Lui \& Hays, 2002; Remien, Hirky, Johnson, Wenhardt, Whittier, 2006; Posse \& Baltussen, 2009).
Another factor that aided adherence as found by the study was availability of drugs which was statistically and significantly rebated to adherence to ART $(p=0.008)$. Respondents receive drugs at the facility for free which motivate them to adhere to refill schedules. These drugs are mainly antiretroviral drug combinations that are subsidized. The supply system also ensures that each respondent received drugs when he or she came for refill to ensure continuity of treatment. As indicated by WHO (2015; 2009), without effective drug supply system, adherence to ART cannot be achieved. Health workers at the study facilities were informed on the need to have regular drug supply to respondents which accounted for their ability to adhere to treatment.

Other service delivery factors that influenced adherence to treatment were health education in the form of counselling $(p=0.018)$, and monitoring. These activities were done on regular basis at the health facilities for HIV patients and their families. Respondents received regular counselling which informed their positive behaviour towards ART adherence. Health promotion activitis therefore facilitate adherence to ART by informing patients on how HIV is managed and how to live a normal life in good health and should be carried out by all health facilities that provide ART services. For respondents at the Sunyani Municipal hospital, the location of clinic days is a threat to stigma for them. HIV and AIDS cases are handled with other out-patient department cases. This exposed their clients to stigma which is a threat to ART adherence. There is thus, the need for a separate facility for HIV cases to enhance service delivery.

With regards to barriers to ART adherence, respondents indicated delay in service delivery, drug scheduling, cost of non-ART drugs and transportation cost as the main barriers to ART adherence. There are different appointments for drugs and consultations which made respondents spend much on transportation. Transportation cost for drug refill has been identified as a barrier by other studies (Hardon, Akurut \& Comoro, 2007; Kangee \& Delport, 2010; Mills, et al., 2006; Trzynka \& Erlen, 2004). In addition, delay in service delivery especially at the pharmacy is a challenge for most respondents. This delay was associated to workers being late to work most of the time, and preferential treatment given to patients who are familiar to health workers. This was a major concern since some respondents have to stay away from their workplaces to seek healthcare. Finding excuses all the time to leave work for the clinic is difficult for a bt of patients especially those that are hiding their HIV status from colleagues, and is therefore a challenge to ART adherence (Hardon et al., 2007). 
From the perspectives of the health professionals, non-availability of drugs, inadequate personnel including doctors, nurses, and counsellors, insufficient supply of logistics for the treatment of HIV and AIDS like reagent for testing CD4 count, among others impede the success of ART efficiency as was abo indicated by Padarath, Searle and Esu-Williams in 2006. The Sunyani Municipal Hospital for instance had no clinician to attend to HIV and AIDS clients. Health professionals lamented that there are increasing numbers of patients with few staff to handle them. This makes it stressful dealing with HIV and AIDS clients. Some health professionals indicated that some patients who felt healthy and refused to adhere to clinic schedules, but were found to refil their drugs on schedule, made the treatment procedure incomplete and made identification of defaulters inaccurate as well.

There were no differences in adherence to ART among patients of the two study facilities. This may be attributed to the fact that the two facilities share similar service delivery structures. Responses from health professionals indicated that the study facilities shared the same ART adherence issues. They used identical procedures to attend to clients and had clients with comparable demographic and social characteristics. Both facilities attend to clients from Brong-Ahafo and beyond, and also, employ national guidelines which are in harmony with the WHO measure for treatment of HIV and AIDS.

It should be noted however, that the findings of the study are limited to patients who patronize the study facilities, and cannot be generalized to all Ghanaian HIV and AIDS patients who use other facilities, though these findings may be similar to comparable facilities across the country. Similar studies may therefore be conducted across designated HIV facilities in the country to ascertain empirically, the factors that influence ART adherence so as to effectively improve HIV management in Ghana.

\section{Conclusion}

Adherence to antiretroviral therapy is crucial for sustained health among HIV patients, and it is dependent on the individual, social, and facility-based support systems. Individuals living with HIV and AIDS would be committed to improving their health and lining long for their families, if these factors are positive. Hence, some barriers to treatment adherence, such as different schedules of appointment for drugs and consultations, unavailability of drugs and health personnel, delay in service delivery at various departments in the health facility, should be addressed holistically by all ART stakeholders. It may also be worthwhile to consider subsidizing non-antiretroviral drugs especially for patients who cannot afford, but cannot do without them, as this may heighten their commitment to adhering to antiretroviral therapy.

\section{References}

Afolabi, B. A., Afolabi, A. A., MA, O., \& Olowookere, S. A. (20/3). Roles of Family Dynamics on Adherence to Highly Active Antiretroviral Therapy among People Living with HIVIAIDS at a Tertiary Hospital in Osogbo, South-West Nigeria. African Health Science, I3(4).

Ampofo, W. (2009). Current Status of HIV IAIDS Treatment, Care and Support Service in Ghana. Ghana Medical Journal, 43(4)

Bailey, H., Thorne, C., Malyuta, R., Townsend, C. L., Semenenko, I., \& C ortina-Borja, M. (20I4).Adherence to Antiretroviral Therapy During Pregnancy and the First Year Postpartum among HIV-positive Women in Ukraine . BMC Public Health, I 4.993.

Beach, M. C., Keruly, J., \& Moore, R. D. (2006). Is the Quality of the Patient-Provider Relationship Associated with Better Adherence and Health Outcomes for Patients with HIV? J GEN INTERN MED, 21:66I-665

Boyarinova, G. (2007). Antiretroviral HIV Therapy at TASO Clinic in Mulago Hospital in Kampala, Uganda: Medical, Cultural. Nursing, Allied Health and Health education, I(I).

Carclucci, J., A., K., Pheneberger, R., Shepherd, B., Jenkins, C., Spurrier, J., \& Vermund, S. (2008). Predictors of Adherence to Antretroviral Therapy in Rural Zambia. J. Acquired Immune Deficiency Syndrome, 15; 47(5):615-622.

Chensney, M., Morin, M., \& Sherr, L. (2000). Adherence to HIV Combination Therapy. Social Science Medicine, 50, 15599- 1605.

Conway, B. (2007). The Role of Adherence to Antiretroviral Therapy in the Management of HIV Infection. Journal of Acquired Immune Deficiency Syndrome, 45:SI4-SI8.

Curioso, W. H., Kepka, D., Cabello, R, Segura, P., \& Kurth, A. E. (20I0). Understanding the Facilitators and Barriers of Antretroviral Adherence in Peru: A Qualitative Study. BMC Public Health, 10:1 3.

Fogarty, L., Roter, D., Larson, S., Burke, J., Gillespie J., \& Richard, L (2002). Patient Adherence to HIV Medication Regimen: A Review of Published and Abstract Reports. Patient Education and Counselling, 46, 93-108.

Fredriksen-Goldsen, K. I., Shiu, C.-S., Starks, H., Chen, W.-T., Simoni, J., Kim, H.-J. Zhang, F. (20II). "You Must Take the Medications for You and for Me": Family Caregivers Promoting HIV Medication Adherence in China. AIDS Patient Care and STDs, 25(I2). 
Ghana AIDS Commission. (2006). AdherenceResistance Relationship for Protease and nonnucleoside Reverse Transcriptase Inhibitor Explained by Virological Fitness. Ghana: Ghana AIDS Commission.

Ghana AIDS Commission. (20I3). Utilizing Strategic Information for Effective National HIV and AIDS Response. National HIV/AIDS Research Confrence (NHARCON) 10th - 13th September. Ghana: Ghana AIDS Commission.

Gokarn, A., Narkhede, M. G., Pardeshi, G. S., \& Doibale, M. K. (20|2). Adherence to Antretroviral Therapy. JAPI.

Golin, C., Lui, H., \& Hays, R. (2002). A Prospective Study of Predictors of Adherence to Combination Antretroviral Medication. General Internal Medicine, 17:756-765.

Grierson, J., Koelmeyer, R., Smith, A., \& Pitts, M. (20II). Adherence to Antiretroviral Therapy: Factors Independently Associated with Reported Difficulty Taking Antiretroviral Therapy in A National Ample of HIV-Positive Australians. HIV Medicine, 12, 562-569.

Hanif, H., Bastos, F. I., Malta, M., Bertoni, N., Surkan, P. J., Winch, P. J., \& Kerrigan, D. (20/3).Individual and Contextual Factors of Influence on Adherence to Antiretrovirals among People Attending Public Clinics in Rio de Janeiro, Brazil. BMC Public Health, 13:574.

Hardon, A. P., Akurut, D., \& Comoro, C. (2007). Hunger, Waiting Time and Transport Costs: Time to Confront Challenges to ART Adherence in Africa. AIDS Care, 19:658-665.

Hardon, A., Davey, S., Gerritis, T., Hodgkin, C., Amsterda, H., Irunde, J., Nakiyemba, R. (2006). The Challenges of Antiretroviral Therapy Treatment: Studies from Botwana, Tanzania and Uganda. Geneva: WHO.

Holstad, M. K., Pace, J. C., De, A. K., \& Ura, M. D. (2006). Factors Associated With Adherence to Antretroviral Therapy. Journal of the Association of Nurses in AIDS Care, 17 (2)4- I5.

Horne, R., Cooper, V., Gellaitry, G., Date, L, \& Fisher, M. (2007). Patient's Perception of Highly Active Antretroviral Therapy in Relation to Treatment Uptake and Adherence. Epidemiology and Social Science.

Kagee, A., \& Delport, T. (2010). Barriers to Adherence to Antiretroviral Treatment: The Perspectives of Patient Advocates. Journal of Health Psychology, 15: I00I.

Karcher, H., A., O., Odera, J., Kurz, A., \& Harms, G. (2007). Risk Factors for Treatment Denial and Loss to Follow-up in an Antiretroviral Treatment Cohort in Kenya. Tropical International Health, 12(5)687-94.
Lucas, G., Chaisson, R., \& Moore, R. (1999). Highly Active Antiretroviral Therapy in a Large Urban Clinic: Risk Factors for Virological Failure and Adverse Drug Reactions. Annals of Internal Medicine, I3I(2); 8I-7.

Luszczynska, A., Sarkar, Y., \& Knoll, N. (2007). Received Social Support, Self-Efficacy

and Finding Benefits in Disease Predictors of Physical Functioning and Adherence to antiretroviral therapy. Patient Education and Counseling, 37-42. Mills, E., Nachega, J., Buchan, I., Orbinski, J., Attaran, A., Singh, S., Bangsberg, D. (2006). Adherence to Antiretroviral Therapy in Sub-Saharan Africa and North America. A Meta- Analysis. JAMA, 296(6) 679-690.

Ministry of Health, \& Ghana Health Service. (2010). Guidelines for Antiretroviral Therapy in Ghana. Ghana: $\mathrm{MOH} / \mathrm{GHS}$.

Morris, J., Marzon, M., Dandy, N., \& O'Brien, L. (20/2). Theories and Models of Behavior and Behavior Change. Forest Research.

Mshana, H. G., Wamoyi, J., Busza, J., Zaba, B., Changalucha, J., Kalumya, S., \& Urassa, M. (2006). Barriers to Accessing Antretroviral Therapy in Kisesa, Tanzania: A Qualitative Study of Early Rural Referrals to the National Program. AIDS Patient Care and STDs, 20(9).

Murphy, D. A., Roberts, J. K., Martin, D. J., Marelich, W., \& Hoffman, D. (2000). Barriers to Antiretroviral Adherence among HIV-Infected Adults. AIDS Patient Care and STDs, I4(I).

Murray, L. K., McCurleya, K. S., Theaa, E., M., D., Scotta, N., Miya, M. . . . Boltonc, P. (2009). Barriers to Acceptance and Adherence of Antiretroviral Therapy in Urban Zambian Women: A Qualitative Study. AIDS Care, 2I(I): 78.

Nacheba, J. B., Knowlton, R. A., Deluca, A., Scheman, H., Watkinson, L., Efron, A. . . . Maartens, G. (2006). Treatment Supporter to Improve Adherence to Antiretroviral Therapy in South African Adults. Journal of Acquired Immune Decificiency Syndrom, 43:I 27-I 33.

National AIDS Control Programme. (20II). HIV Sentinel Survey. Ghana: Ministry of Health..

Ngarina, M., Popenoe, R., Kilewo, C., Biberfeld,G., \& Ekstrom, A. M. (20I3). Reasons for Poor Adherence to Antiretroviral Therapy Postnatally in HIV-I Infected Women Treated for Their Own Health: Experiences From the Mitra Plus Study in Tanzania . BMC Public Health, 13:450.

Obrirkorang, C. Selleh, P., Abledu, K., \& Fofie, O . (20I3). Predictors of Adherence to Antiretroviral among HIV/AIDS Patients in the Upper West Region of Ghana. ISRN AIDS. 
Ohene, S., \& Forson, E. (2009). Care of Patient on Antiretroviral Therapy in Kumasi Metropolis. Ghana Medical Journal.

Obwookere, S. A., Fatiregun, A. A., Aknyemi, J. O., Bamgboye, A. E., \& Osagbemi, G. K. (2008). Prevalence and Determinants of Non- Adherence to Highly Active Antretrovira I Therapy among People Living with HIV/AIDS in Ibadan, Nigeria. J Infect Developing Countries, 2(5):369-372.

Padarath, A., Searle, C., \& Esu-Williams, E. (2006). Understanding Barriers to Community Participation in HIV and AIDS Services. The Population Council Inc.

Posse, M., \& Baltussen, R. (2009). Barriers to Access to Antretroviral Treatment in Mozambique, as Percieved by Patient and Health Workers in Urban and Rural Settings. AIDS Patient Care.

Reif, S., Golin, C. E., \& Smith, S. R. (2005). Barriers to Accessing HIV/AIDS Care in North Carolina: Rural and Urban Differences. AIDS Care, I7(5): $558 / 565$.

Remien, R., Hirky, A., Johnson, M., Weinhardt, L., \& Whittier, D. (2006). Adherence to Medication Treatment: A Qualitative Study of Faciltators and Barriers among Sample of HIV Men and Women in Four US cities. AIDS Behavior, 1:61-72.

Rintamaki, L. S., Davis, T. C., Skripkauskas, S., Bennette, C. L., \& Wolf, M. S. (2006). Social Stigma Concerns and HIV Medication Adherence. AIDS Patient Care and STDs, 20 (5).

Simoni J.M., K. A. (2006). Self-Report Measures of Antretroviral Therapy Adherence: A Review of Recommendations for HIV Research and Clinical Management. AIDS Behaviour, 10(3):227- 45.

Spirea, B., Durana,S., Souvilea, M., Leportb, C., Fran-coisRaffi, C., \& Moattia, J.-P. (2002). Adherence to Highly Active Antretroviral Therapies (HAART) in HIV-Infected Patients: From a Predictive to a Dynamic Approach. Social Science \& Medicine, 54, |48|-| 496.

Trzynka, S., \& Erlen, J. (2004). HIV Disease Susceptbility in Women and Barriers to Adherence. Medsurg Nursing, 97- 104.

UNAIDS. (2012). World AIDS Day Report Result. UNAIDS.

UNAIDS. (2015). Global AIDS Response Progress Reporting 2015. Geneva: UNAIDS.

UNAIDS, \& WHO. (2003). A History of the HIVIAIDS Epidemic with Emhasis on Africa. Geneva:WHO.

UNAIDS, \& WHO. (2007). Prevalence of HIV and AIDS Epidemic Update. Geneva: WHO.

Walker, L., Reid, G., \& Cornell, M. (2004). Waiting to Happen. Cape Town: Double Storey Books.
Wanyama, J., Castenuvo, B., Wandera, B., Mwebaze, P., Kambugu, A., \& Bangberg, D. (2007). Belief in Devine Healing Can Be A Barrier to Antiretroviral Adherence in Uganda. AIDS, II:2I(II):1486-7.

WHO (20I5). World Health Statistics 2015. Geneva: WHO.

Online at: www.who.int/gho/publications/.../20I5/en/ 
African Population Studies Vol. 30, No. 2 (Supp.), 2016 